\title{
SERVE EFFICIENCY DEVELOPMENT INDICATES AN EXTENDED WOMEN'S TENNIS WORLD CLASS COHORT: ANALYSING 14 YEARS OF LADIES WIMBLEDON CHAMPIONSHIPS - IMPLICATIONS FOR COACHING
}

original paper

( ) University School of Physical Education in Wroclaw

DOI: https://doi.org/10.5114/hm.2021.100011

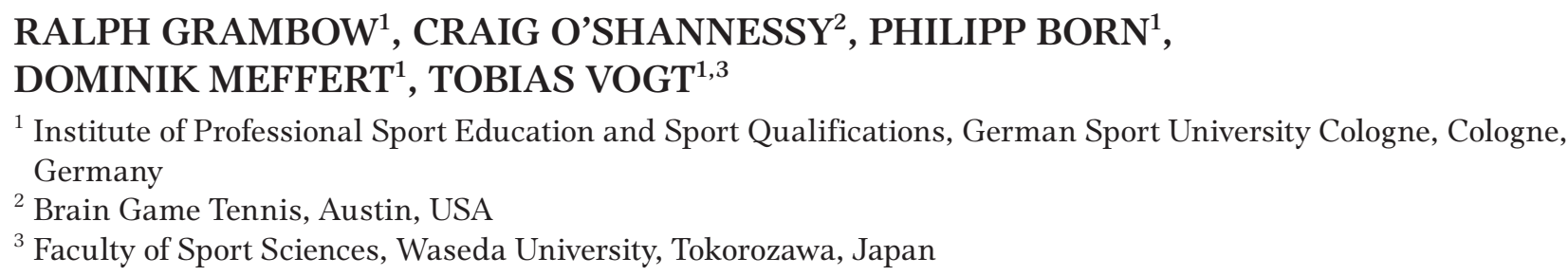

ABSTRACT

Purpose. How crucial is good serving to succeed in modern days women's world class tennis? The study aimed to systematically analyse serve efficiency and serving behaviour in elite women's tennis over 14 years to identify possible training patterns.

Methods. Analyses included historical data on all matches at the Ladies Wimbledon Championships of 2002-2015 (matches: $n=1771$; service games: $n=37,717$; serves: $n=248,135$ ). The study focused on 2 main comparisons, serve efficiency development in 2002-2015 and possible differences within the women's tennis world class, between the $1^{\text {st }}$ (matches: $n=1562$; service games: $n=33,150$; serves: $n=218,028$ ) and $2^{\text {nd }}$ tournament week results (matches: $n=209$; service games: $n=4567$; serves: $n=30,107$ ).

Results. An increase over time was observed for the percentages of service games won $(p<0.001), 1^{\text {st }}$ service points won $(p<0.05)$, and aces served $(p<0.01)$, whereas double faults served $(p<0.05)$ and serve and volley points played $(p<0.001)$ decreased significantly. Direct comparisons of the $1^{\text {st }}$ and $2^{\text {nd }}$ tournament week results favour players competing in the $2^{\text {nd }}$ tournament week, showing significant advantages in the percentages of service games won $(p<0.01), 1^{\text {st }}$ service points won $(p<0.05)$, and aces served $(p<0.001)$.

Conclusions. An increased serve efficiency over time was observed, particularly for $1^{\text {st }}$ tournament week results, indicating a more extended women's world class cohort. However, direct comparisons favour players competing in the $2^{\text {nd }}$ tournament week.

Key words: world class women's tennis, service game, match strategy, training, practice

\section{Introduction}

Elite tennis is dominated by great players and legends, no matter if we take a look at women's or men's tennis. Whilst in men's tennis only 4 players ranked No. 1 in the world since 2006, 17 different women reached the top during the same time (Association of Tennis Professionals [ATP] and Women's Tennis Association [WTA] homepage, Rankings). Serena Williams is based on her time as No. 1 (319 weeks) and her number of Grand Slam titles (23) the most successful active female tennis player (WTA homepage, Rankings).
In order to be so successful and win all these titles, Serena Williams dominates with her powerful baseline game and her even more powerful serve, which is commonly known as the best serve in women's tennis (history), especially under her opponents (e.g. current No. 2 , Simona Halep: 'best serve forever,' WTA homepage). Her serve seems to separate her from her opponents, which underlines the value of the serve in modern tennis. Whilst in elite men's tennis the importance of the serve, return, and opening shots is well known and analysed [1-3], a longitudinal research focusing on women's serve efficiency might benefit a better un-

Correspondence address: Ralph Grambow, Institute of Professional Sport Education and Sport Qualifications, German Sport University Cologne, Am Sportpark Müngersdorf 6, 50933 Köln, Germany, e-mail: r.grambow@dshs-koeln.de

Received: April 23, 2020

Accepted for publication: August 6, 2020

Citation: Grambow R, O’Shannessy C, Born P, Meffert D, Vogt T. Serve efficiency development indicates an extended women's tennis world class cohort: analysing 14 years of Ladies Wimbledon Championships - implications for coaching. Hum Mov. 2021;22(2):43-52; doi: https://doi.org/10.5114/hm.2021.100011. 
R. Grambow, C. O’Shannessy, P. Born, D. Meffert, T. Vogt, Ladies serve efficiency development

derstanding of success in elite women's tennis. Elite men win $84 \%$ of their service games, $75 \%$ of $1^{\text {st }}$ serve points, and $52 \%$ of their $2^{\text {nd }}$ serve points, while serving more than $10 \%$ of aces [3]. Comparable to men's serving, Serena Williams has served the fastest women's serve (122 mph) at the Ladies Wimbledon Championships 2019. However, in general women's serve efficiency remains to be elucidated.

Certainly, tennis players and tennis coaches are most interested in being as successful as possible in reaching the top levels of professional tennis. Therefore, it is most important to understand the characteristics of the sport in order to identify what makes tennis players successful and, thus, what is needed to win titles at the elite level. The International Tennis Federation (ITF) and both the ATP and the WTA deliver several statistics from their matches, serving as information for the commentators and the interested audience but also for the players and coaches in order to improve their own game or prepare for their upcoming opponents. Encouraged by the ITF [4] and the ongoing interest in scientific achievements, scientists also use these statistics to recognize and underline past, current, and possible future elements of the sport.

Whilst elite men's tennis [1, 3, 5-9] has regularly been in the focus of scientific analyses and research, only a small number of studies compare gender-specific differences [10-15]. In fact, elite women's tennis [16-18] often remains to be elucidated scientifically, especially regarding long-term analyses.

Therefore, the present study focused on the development in serve efficiency over an extended period of time, by analysing all singles matches played at the Ladies Wimbledon Championships between 2002 and 2015, similar to recently reported male long-term analyses [3]. The 4 Grand Slam tournaments are the only tournaments in the professional tennis calendar which are played over 2 full weeks. They are held with 128 player draws, giving the players the chance of winning the most world ranking points (e.g. 2000 ATP/WTA points) and the highest prize money (e.g. £2,350,000 for the 2019 Gentlemen's or Ladies' Singles Winner). Wimbledon is the only Grand Slam played on grass court, while the Australian Open and the US Open are played on hardcourt and the French Open is the only one played on clay court. With this, research endeavours regarding the effects of different surfaces on a match outcome suggest different results. Del Corral and Prieto-Rodríguez [19] revealed no effects of the court surface on a match outcome. Weber and Born [20] and Weber et al. [21] report no effects on rally length, whereas O’Donoghue and Ingram [14] suggest the court surface to be the main indicator for a match outcome and game style. Grass court is known as the fastest surface, being serve-beneficial [7]. The importance of the serve, return, and opening shots in modern tennis is well-documented [1-3, 6] and suggested to be even greater on grass court [12]. With respect to this previous research focused on elite men's tennis, the present study aims to prove increased serve efficiency in elite women's tennis, taking more than a decade of Ladies Wimbledon Championships into account.

The study examines the serve performance, serve success, and serve strategy development over 14 years of Ladies Wimbledon Championships, focusing on world class players, divided into the $1^{\text {st }}$ and $2^{\text {nd }}$ tournament week. It is hypothesized that winning percentages of service games, including $1^{\text {st }}$ and $2^{\text {nd }}$ serve points won, increased over the course of 14 years in elite women's tennis, while serve parameters, like aces and double faults, increased and decreased, respectively. It is also hypothesized that comparing findings of the total tournament, the $1^{\text {st }}$ tournament week and the $2^{\text {nd }}$ tournament week results indicate what separates even more successful women (last 16) from successful women (last 128). The findings may serve as indicators of what is needed to succeed at the highest levels on the way to the ultimate goal in tennis, winning a Grand Slam title.

\section{Material and methods}

In collaboration with Brain Game Tennis and with approval of the German Sport University Cologne Ethics Committee, longitudinal data concerning Ladies Wimbledon Championships 2002-2015 were retrieved from the Wimbledon Information System (presented by IBM). The collected data included serve percentages for service games, $1^{\text {st }}$ and $2^{\text {nd }}$ serves, service parameters such as aces and double faults, as well as usage and winning percentages for serve and volley points. In total, 1771 matches with 37,717 service games comprising 248,135 serves of which 10,525 were aces and 12,100 were double faults were included for analyses.

Following the research methodology of an earlier study by Grambow et al. [3], who focused on elite men's tennis, the present study concentrated on 2 main analyses. At first, historical data were analysed for possible developments and changes of elite women's serve behaviour and efficiency (i.e. serve success, serve performance, serve strategy) between 2002 and 2015. Earlier research mostly analysed much smaller sample sizes, focusing on semi-finals to the final or whole tournaments to one year or combined different Grand Slam 
tournaments [11, 22, 23], but to the knowledge of the authors, there are no published data of elite women's tennis covering such a long period of time, especially not for the second part of the analyses. Taking 2002 as the starting point seemed appropriate owing to the rebuilding of all grass courts after the 2001 championships. Organizers chose to build the new courts out of $100 \%$ perennial rye grass, while the old courts were a 70-30 split of rye grass and creeping red fescue. In addition to this, the ITF decided to use new balls in 2002, which would play faster or slower depending on the surface.

The second focus referred to possible differences within the examined women's world class, by further separating the data into $1^{\text {st }}$ tournament week totals and $2^{\text {nd }}$ tournament week totals, in order to analyse what set apart even more successful players (e.g. players competing in the $2^{\text {nd }}$ tournament week, last 16) from successful players (e.g. players competing in the $1^{\text {st }}$ tournament week, last 128). Spreadsheets were compiled for all 7 played rounds in each of the 14 analysed years with the following parameters, which are widely accepted as valid measures for serve efficiency [24, 25], for the comparison over time:

- the number of $1^{\text {st }}$ and $2^{\text {nd }}$ serves won by all players (i.e. serve success);

- the number of service games won by all players (i.e. serve success);

- the number of aces served by all players (i.e. serve performance);

- the number of double faults served by all players (i.e. serve performance);

- the number of points played by each player when following a serve and volley strategy (i.e. serve strategy);

- the number of points won by each player when following a serve and volley strategy (i.e. serve strategy).

The recorded parameters for serve efficiency were categorized and assigned to 3 different groups: serve success, serve performance, and serve strategy. While the first category, serve success, shows how successful a player was against her opponents (e.g. service winners, multiple shot rallies, etc.) during serving (i.e. percentages of service games won, $1^{\text {st }}$ serve points won, $2^{\text {nd }}$ serve points won), the second category, serve performance, includes only served aces and double faults, since these parameters are defined only by the server and no shots being played by her opponent. The third category, serve strategy, contains all points being played and won while playing serve and volley. Historically, players used this special strategy in Wimbledon, following their serve directly to the net [26].
Moreover, $1^{\text {st }}$ tournament week totals and $2^{\text {nd }}$ tournament week totals were compared directly. Results of rounds one, two, and three were summarized for $1^{\text {st }}$ tournament week totals (matches: $n=1562$; service games: $n=33,150$; serves: $n=218,028$ ), whereas results of rounds four, quarter-finals, semi-finals, and final were summarized for $2^{\text {nd }}$ tournament week totals (matches: $n=209$; service games: $n=4567$; serves: $n=$ 30,107).

Statistical procedures were performed with the use of the SPSS Statistics for Macintosh, version 26.0. (IBM Corp., Armonk, USA), as well as Excel 2016 (Microsoft Corp., Redmond, USA).

A one-way analysis of variance (ANOVA) was applied for a direct comparison of $1^{\text {st }}$ tournament week totals and $2^{\text {nd }}$ tournament week totals, with $2^{\text {nd }}$ tournament week totals normed to the size of a general $1^{\text {st }}$ tournament week (i.e. 112 matches). Effect sizes [27] were calculated and interpreted as small $(f=0.10)$, medium $(f=0.25)$, and large $(f=0.40)$. Spearman's rank correlations analyses were used for the analyses over time, with $0.1 \leq \rho$ (rho) $<0.3$ interpreted as small, $0.3 \leq \rho<0.5$ as medium, and $\rho \geq 0.5$ as large correlations [27], more recently augmented with the categories of very large for $0.7 \leq \rho<0.9$ and extremely large for $\rho \geq 0.9$ [28].

Data in the text and tables are presented as mean percentages. The significance of the results was set at $p<0.001, p<0.01$, and $p<0.05$ for very high significance, high significance, and significance, respectively; trends were accepted for $p<0.10$.

\section{Ethical approval}

The conducted research is not related to either human or animal use.

\section{Results}

\section{Serve success}

Analyses for service games won (total tournament: minimum $66.69 \%$ in 2002, maximum $71.52 \%$ in 2010 ; last 16: minimum $65.05 \%$ in 2003, maximum $75.79 \%$ in 2009; Table 1) showed changes from 2002 to 2015 for the total tournament $(p<0.001 ; \rho=0.85)$ and the $1^{\text {st }}$ tournament week ( $\left.p<0.01 ; \rho=0.71\right)$, but not for the $2^{\text {nd }}$ tournament week ( $p=0.73 ; \rho=0.1$; Figure 1 ). A direct comparison between the 2 tournament weeks revealed advantages in favour of players competing in the $2^{\text {nd }}$ tournament week $(p<0.01 ; f=0.55$; Table 1$)$.

Analyses for points won following $1^{\text {st }}$ serves (total tournament: minimum $64.10 \%$ in 2002 , maximum 


\section{HUMAN MOVEMENT}

R. Grambow, C. O’Shannessy, P. Born, D. Meffert, T. Vogt, Ladies serve efficiency development

$66.98 \%$ in 2015 ; last 16 : minimum $64.42 \%$ in 2013 , maximum $70.11 \%$ in 2009 ; Table 1) showed changes from 2002 to 2015 for the total tournament $(p<0.05$; $\rho=0.61)$ and the $1^{\text {st }}$ tournament week $(p<0.05 ; \rho=$ 0.58 ), but not for the $2^{\text {nd }}$ tournament week ( $p=0.84$; $\rho=0.06$; Figure 1). A direct comparison revealed advantages for the $2^{\text {nd }}$ tournament week totals compared with $1^{\text {st }}$ tournament week totals $(p<0.05 ; f=0.43$; Table 1).

Analyses for points won following $2^{\text {nd }}$ serves (total tournament: minimum $45.00 \%$ in 2003 , maximum $46.93 \%$ in 2010 ; last 16 : minimum $41.78 \%$ in 2003 , maximum $49.75 \%$ in 2009 ; Table 1) showed a trend to change from 2002 to 2015 for the total tournament $(p<0.10 ; \rho=0.48)$, but not for the $1^{\text {st }}$ tournament week $(p=0.12 ; \rho=0.43)$ and $2^{\text {nd }}$ tournament week $(p=0.97$; $\rho=-0.01$; Figure 1). A direct comparison of both tournament weeks revealed no significant differences $(p=$ 0.64; $f=0.09$; Table 1).

\section{Serve performance}

Analyses for served aces (total tournament: minimum $3.55 \%$ in 2002, maximum 5.17\% in 2010; last 16: minimum $4.00 \%$ in 2003 , maximum $7.04 \%$ in 2009 ;
Table 1) showed changes from 2002 to 2015 for the total tournament $(p<0.01 ; \rho=0.78)$ and the $1^{\text {st }}$ tournament week ( $p<0.01 ; \rho=0.68)$, but not for the $2^{\text {nd }}$ tournament week ( $p=0.20 ; \rho=0.37)$, whereas analyses for served double faults (total tournament: maximum $5.59 \%$ in 2002, minimum $4.03 \%$ in 2014; last 16: maximum $5.74 \%$ in 2009 , minimum $4.01 \%$ in 2013 ; Table 1) showed changes from 2002 to 2015 for the total tournament $(p<0.05 ; \rho=-0.54)$ and a trend to change for the $1^{\text {st }}$ tournament week $(p<0.10 ; \rho=-0.53)$, but not for the $2^{\text {nd }}$ tournament week ( $p=0.23$; $\rho=-0.35$; Figure 1). A direct comparison revealed advantages for players competing in the $2^{\text {nd }}$ tournament week by serving more aces $(p<0.001 ; f=0.81)$, but demonstrated no significant differences by serving more or less double faults ( $p=0.94 ; f=0.02$; Table 1 ).

\section{Serve strategy}

Analyses for serve and volley points played (total tournament: maximum $4.86 \%$ in 2002 , minimum $0.96 \%$ in 2014 ; last 16 : maximum $9.65 \%$ in 2006 , minimum $0.31 \%$ in 2010 and 2011; Table 1) showed changes from 2002 to 2015 for the total tournament $(p<0.001 ; \rho=-0.96)$ and the $1^{\text {st }}$ tournament week $(p<$

Table 1. Comparison of different tournament weeks

\begin{tabular}{|c|c|c|c|c|c|c|c|c|c|c|c|c|c|c|c|c|}
\hline \multirow{2}{*}{\multicolumn{2}{|c|}{ Category }} & & \multicolumn{14}{|c|}{ Tournament year } \\
\hline & & & 2002 & 2003 & 2004 & 2005 & 2006 & 2007 & 2008 & 2009 & 2010 & 2011 & 2012 & 2013 & 2014 & 2015 \\
\hline \multirow{9}{*}{ 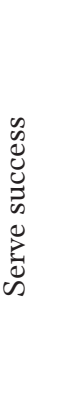 } & Ser & ent & 66.69 & 67.67 & 68.05 & 67.01 & 68.20 & 68.91 & 68.27 & 68.45 & 71.52 & 69.45 & 69.40 & 68.38 & 69.49 & 69.6 \\
\hline & games & $1^{\text {st }}$ week & 65.81 & 68.04 & 67.73 & 66.30 & 68.25 & 68.64 & 67.34 & 67.48 & 70.99 & 69.57 & 69.07 & 68.50 & 69.24 & 69.2 \\
\hline & won (\%) & $2^{\text {nd }}$ week & 74.10 & 65.05 & 70.25 & 72.05 & 67.80 & 70.59 & 74.93 & 75.79 & 75.40 & 68.49 & 71.68 & 67.54 & 71.63 & 72.46 \\
\hline & $1^{\text {st }}$ serve & nt & 64.10 & 65.15 & 64.86 & 64.54 & 64.25 & 64.99 & 64.68 & 65.27 & 66.40 & 65.31 & 65.57 & 64.24 & 65.41 & 66.9 \\
\hline & points & $1^{\text {st }}$ week & 63.56 & 65.09 & 64.93 & 64.29 & 64.13 & 64.72 & 64.07 & 64.69 & 66.13 & 65.18 & 65.26 & 64.22 & 65.34 & 66.82 \\
\hline & won (\%) & $2^{\text {nd }}$ week & 68.65 & 65.56 & 64.45 & 66.23 & 65.23 & 66.69 & 68.80 & 70.11 & 68.41 & 66.30 & 67.63 & 64.42 & 66.08 & 68.11 \\
\hline & $2^{\text {nd }}$ serve & & & 45.00 & 45.55 & 4 & 20 & 46.15 & 46.57 & 45.30 & 4 & 46.77 & 46.24 & 46.42 & 40.07 & 45.51 \\
\hline & points & $1^{\text {st }} \mathrm{we}$ & 45.75 & 45.43 & 45.52 & 45.12 & 46.43 & 46.31 & 46.78 & 44.71 & 46.64 & 47.08 & 46.36 & 47.00 & 46.40 & 45.57 \\
\hline & & $2^{\text {nd }}$ week & 48.67 & 41.78 & 45.74 & 47.14 & 44.67 & 45.11 & 45.09 & 49.75 & 49.11 & 44.39 & 45.35 & 42.45 & 49.13 & 45.0 \\
\hline \multirow{6}{*}{ 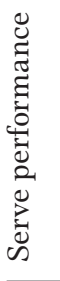 } & \multirow{3}{*}{ Aces (\%) } & & 3.55 & 3.91 & 4.22 & 3.64 & 3.77 & 4.25 & 3.71 & 4.15 & 5.17 & 4.55 & 4.35 & 4.25 & 4.89 & 4.9 \\
\hline & & $1^{\text {st }}$ week & 3.40 & 3.89 & 4.04 & 3.56 & 3.66 & 4.13 & 3.39 & 3.79 & 5.02 & 4.43 & 4.00 & 4.22 & 4.96 & 4.8 \\
\hline & & $2^{\text {nd }}$ week & 4.86 & 4.00 & 5.44 & 4.23 & 4.61 & 5.02 & 5.96 & 7.04 & 6.29 & 5.47 & 6.75 & 4.48 & 4.27 & 5.9 \\
\hline & \multirow{3}{*}{$\begin{array}{l}\text { Double } \\
\text { faults (\%) }\end{array}$} & $\mathrm{T}$ & 5.59 & 5.27 & 5.12 & 5.14 & 4.68 & 4.84 & 4.77 & 5.27 & 4.70 & 4.70 & 4.84 & 4.23 & 4.0 & 5.16 \\
\hline & & $1^{\text {st }}$ week & 5.68 & 5.33 & 5.22 & 5.19 & 4.58 & 4.82 & 4.84 & 5.21 & 4.66 & 4.60 & 4.90 & 4.26 & 3.95 & 5.30 \\
\hline & & $2^{\text {nd }}$ week & 4.86 & 4.80 & 4.45 & 4.79 & 5.36 & 5.02 & 4.33 & 5.74 & 5.01 & 5.52 & 4.41 & 4.01 & 4.70 & 4.1 \\
\hline \multirow{6}{*}{ 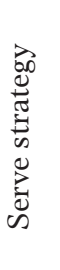 } & \multirow{3}{*}{$\begin{array}{l}\text { Serve and } \\
\text { volley points } \\
\text { played }(\%)\end{array}$} & Total tour & 4.86 & 4.63 & 4.44 & 3.98 & 3.76 & 1.78 & 2.08 & 2.26 & 1.69 & 1.05 & 1.22 & 1.17 & 0.96 & 1.2 \\
\hline & & $1^{\text {st }}$ week & 5.03 & 5.20 & 4.70 & 3.91 & 2.97 & 1.64 & 2.22 & 2.22 & 1.88 & 1.69 & 1.17 & 1.06 & 0.93 & 1.30 \\
\hline & & $2^{\text {nd }}$ week & 3.44 & 0.59 & 2.73 & 4.45 & 9.65 & 2.66 & 1.10 & 2.59 & 0.31 & 0.31 & 1.60 & 1.89 & 1.23 & 0.8 \\
\hline & \multirow{3}{*}{$\begin{array}{l}\text { Serve and } \\
\text { volley points } \\
\text { won (\%) }\end{array}$} & arnament & 63.32 & .51 & 66.62 & 65.76 & 64.96 & .59 & 65.68 & 65.63 & 62.09 & 61.15 & 62.62 & 64.68 & 68.45 & 70.7 \\
\hline & & $1^{\text {st }}$ week & 64.11 & 65.90 & 66.26 & 65.60 & 64.14 & 68.40 & 64.35 & 63.88 & 61.99 & 60.63 & 62.79 & 63.92 & 67.81 & 70.6 \\
\hline & & $2^{\text {nd }}$ & 53.45 & 41.67 & 70.69 & 66.67 & 66.84 & 64.41 & 84.00 & 77.55 & 66.67 & 83.33 & 61.76 & 67.44 & 72.73 & 72.2 \\
\hline
\end{tabular}


R. Grambow, C. O’Shannessy, P. Born, D. Meffert, T. Vogt, Ladies serve efficiency development

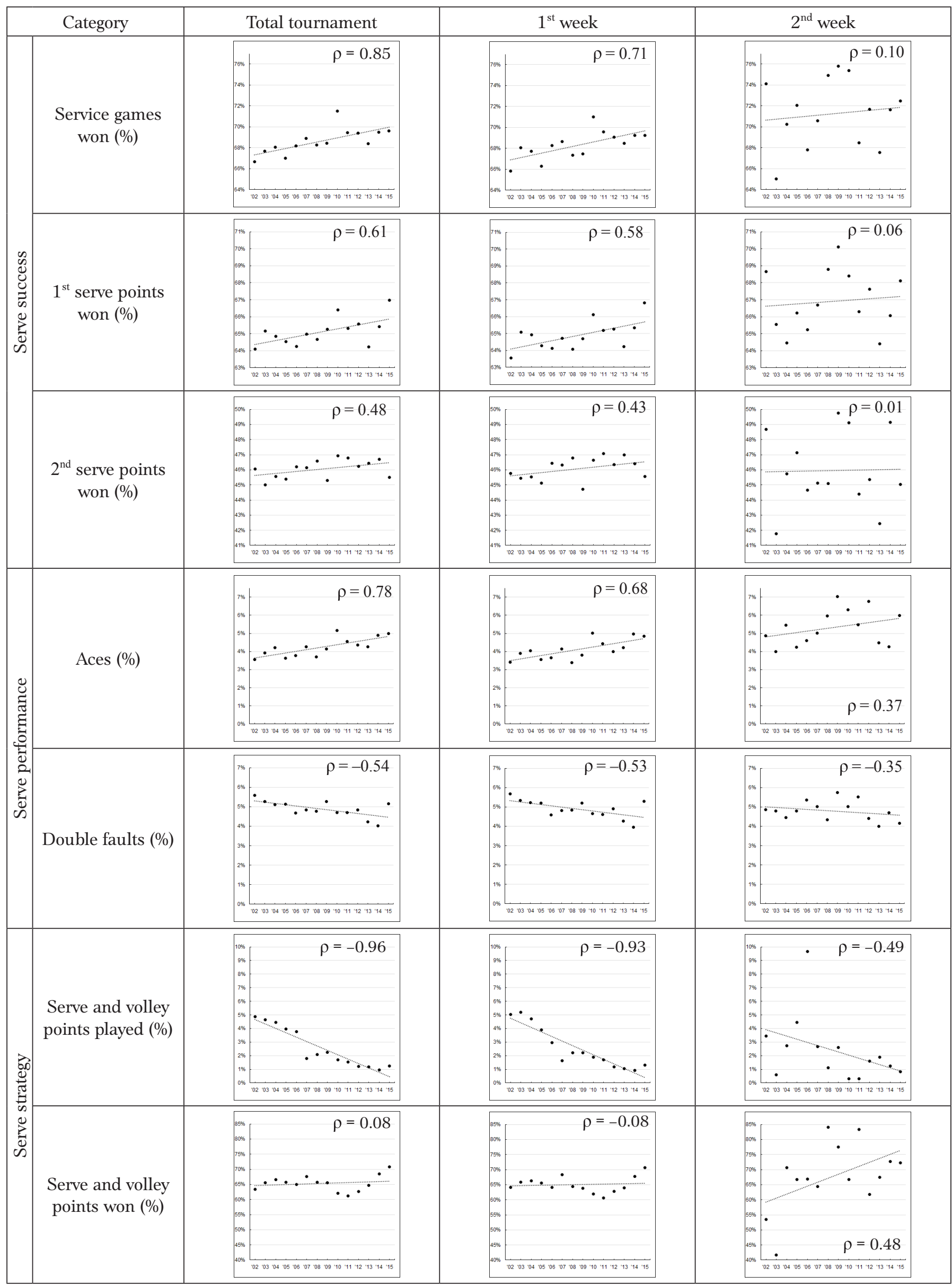

Figure 1. Correlation of different tournament weeks 
R. Grambow, C. O’Shannessy, P. Born, D. Meffert, T. Vogt, Ladies serve efficiency development

$0.001 ; \rho=-0.93)$; the $2^{\text {nd }}$ tournament week presented a trend to change $(p<0.10 ; \rho=-0.49)$, whereas analyses for serve and volley points won (total tournament: minimum $61.15 \%$ in 2011, maximum $70.75 \%$ in 2015 ; last 16: minimum $41.67 \%$ in 2003 , maximum $84.00 \%$ in 2008; Table 1) showed no significant differences for the total tournament ( $p=0.78 ; \rho=0.08)$ and the $1^{\text {st }}$ tournament week $(p=0.78 ; \rho=-0.08)$, but a trend to change for the $2^{\text {nd }}$ tournament week $(p<0.10 ; \rho=$ 0.48 ; Figure 1). A direct comparison of both tournament weeks revealed no differences for serve and volley points played ( $p=0.91 ; f=0.02)$ and serve and volley points won $(p=0.99 ; f=0.0$; Table 1$)$.

\section{Discussion}

The aim of the present study was to find and prove serve efficiency developments in elite women's tennis, by using a longitudinal approach and analysing 14 years of Ladies Wimbledon Championships. The analysed parameters regarding serve success, serve performance, and serve strategy showed significant changes over time for the total tournament in 5 out of 7 categories, for the $1^{\text {st }}$ tournament week totals in 4 out of 7 categories, but none in any category for the $2^{\text {nd }}$ tournament week totals. These findings are in line with earlier results [29]. Furthermore, the present study aimed to find possible differences within the women's world class, by directly comparing $1^{\text {st }}$ and $2^{\text {nd }}$ tournament week totals. The findings revealed significant advantages in favour of the players competing in the $2^{\text {nd }}$ tournament week for served aces and success rates of service games won and $1^{\text {st }}$ serve points won. Similar results were observed in elite men's tennis before [3]. Comparing minimum and maximum achievements for mean values (total tournament results and the $2^{\text {nd }}$ tournament week [last 16] results) regarding serve success and serve performance parameters showed maximum results being closer to today in 9 out of 10 times.

The findings of the comparison over time suggest an increased serve efficiency in elite female tennis at Wimbledon, which may allow an interesting interpretation: tournament totals show an increased number of served aces, as well as increased success rates for the number of service games won and points won after the $1^{\text {st }}$ serve. They also present a decreased number of served double faults. In turn, the findings for $1^{\text {st }}$ tournament week totals show the same significant changes (same categories), only the number of served double faults indicates a statistical trend $(0.05<p<$ 0.10 ) and the findings for $2^{\text {nd }}$ tournament week totals demonstrate no significant changes over time in any of the analysed parameters. The non-existence of any significant increase or decrease in any of the analysed parameters may lead to a conclusion that professional women's tennis has become more competitive and balanced. The observations suggest that the even more successful women (e.g. players competing in the $2^{\text {nd }}$ tournament week at Wimbledon, last 16) were serving at a very high efficiency already more than a decade ago, which separates them from their opponents. Moreover, the present study findings now provide evidence of an increased serve efficiency for tournament totals and $1^{\text {st }}$ tournament week totals, but - as mentioned not for any parameters of $2^{\text {nd }}$ tournament week totals. Thus, the above stated interpretation that the developments over the last years have led to a more balanced women's world class appears to be robust. Following this line of thought, it seems reasonable to reflect that any found developments concerning increased serve efficiency in elite female tennis have mainly taken place in the extended world class. This observed development seems to have continued and even increased, since a very high number of different women reached the top of the world ranking ( 8 different women between 2016 and 2020) and won a Grand Slam tournament (11 different winners in the last 17 Grand Slam tournaments between 2016 and 2020) in recent years.

Another interpretation, e.g. the non-existence of significant developments for $2^{\text {nd }}$ tournament week totals, may indicate a certain stagnation in the absolute top levels of women's tennis, while the extended world class managed to improve and develop their serve efficiency and by this reduce their performance deficit. But since Serena Williams was the winner of the 2002 Ladies Wimbledon Championships and also the winner of the 2015 Ladies Wimbledon Championships (she won 6 times in the analysed 14 years, 7 times in total, after winning 2016; she also won the Australian Open 2017), it also seems reasonable to question a stagnation with respect to the most successful female tennis player of the open era and, on the contrary, suggest the beforehand discussed more balanced women's world class cohort instead.

In order to find out what is necessary to succeed at the elite level in women's tennis (e.g. winning Wimbledon), dividing the women's world class is of relevance, e.g. when comparing the women's $1^{\text {st }}$ tournament week totals (last 128) to women's $2^{\text {nd }}$ tournament week totals (last 16) for the first time. The present study findings showed advantages in favour of women competing in the $2^{\text {nd }}$ tournament week, more specifically winning their service games and points on $1^{\text {st }}$ 
serves at significantly higher rates than women competing in the $1^{\text {st }}$ tournament week. These players also serve significantly more aces. No differences were found regarding served double faults, winning points on $2^{\text {nd }}$ serves, or the usage and success rates of playing serve and volley. Second serve points won are the only analysed parameter which actually showed advantages for (last 128) women competing in the $1^{\text {st }}$ tournament week (e.g. in 8 out of 14 analysed years); this could be directly related with a higher return of serve quality by (last 16 ) women competing in the $2^{\text {nd }}$ tournament week. Consequently, this leads to the assumption that a dominant $1^{\text {st }}$ serve including the capability of hitting aces and a high-quality return of serve (more so returning $2^{\text {nd }}$ serves), but, interestingly, not necessarily a strong $2^{\text {nd }}$ serve including serving only few double faults, increases the chances of playing for the title at Wimbledon. Comparing the absolute numbers over the course of the analysed 14 years showed an interesting ratio of aces vs. double faults in elite women's tennis. While serving 10,525 aces, the players served even more double faults $(12,100)$. This is in contrast to elite men's tennis, where the players served 38,173 aces while hitting 14,420 double faults over the same time span [3]. Comparing $1^{\text {st }}$ tournament week absolute numbers (8925 aces vs. 10,662 double faults) with $2^{\text {nd }}$ tournament week absolute numbers (1600 aces vs. 1438 double faults) underlines the above stated assumption, as women competing in the $2^{\text {nd }}$ tournament week continue to hit double faults but, more importantly, manage to achieve a positive ratio because of their increased number of aces.

The present study reveals improved serve efficiency, which seems to be crucial to succeed at the highest levels of elite tennis, confirming previous research about well-known importance of serve [1, 2, 6], even more so on grass court at Wimbledon compared with the other Grand Slam tournaments [7, 12, 16].

Findings regarding the analysed serve strategies revealed a significant decrease in the use of serve and volley over time. This decrease applies to the total tournament $(p<0.001)$ and to the $1^{\text {st }}$ tournament week totals $(p<0.001)$, but not to the $2^{\text {nd }}$ tournament week totals. These observations are in line with previous results focusing on the 2002-2015 Gentlemen's Wimbledon Championships, with the difference of an additional significant decrease for the $2^{\text {nd }}$ tournament week totals on top to the same decrease in total tournament and $1^{\text {st }}$ tournament week totals [3]. The findings showed no significant changes for the serve and volley winning percentages of total tournament and $1^{\text {st }}$ tournament week totals. A change of game style in modern tennis seems obvious [30]; however, the success rates remained stable at $65 \%$ over the analysed 14 years, similar to previously found, with slightly higher winning percentages for the men's success rates [3]. Although statistically only indicated by trend ( $p=$ 0.08 ), it seems reasonable to discuss the $2^{\text {nd }}$ tournament week totals increase of the serve and volley success rates. Over time, a development from below $60 \%$ to more than $75 \%$ could be revealed, including a variance in mean values ranging from $42 \%$ (in 2003) to $84 \%$ (in 2008) or 83\% (in 2011). However, these numbers have to be taken with care, since the usage rate percentages of the $2^{\text {nd }}$ tournament week totals are rather low (e.g. mean percentage over the 14 years: $2.39 \%$ ), including great variances (e.g. 2006: 9.65\%, 2010 and 2011: $0.31 \%)$. Particularly in years 2010 and 2011, when in the completed $2^{\text {nd }}$ tournament week serve and volley was played for only 6 times, the sample size may be considered as too small to allow for any interpretation.

\section{Limitations}

In science, prospective trials should always be preferred over retrospective analyses. Analysing professional tennis competition at the elite level in order to gain knowledge appropriate to possibly impact on future practice contents is only possible with a retrospective study design, particularly in this case with an amount of data covering a period of 14 years.

Findings regarding the serve success, serve performance, or serve strategy may be influenced by a medical issue as the competing players may not be in their best health condition; however, given the enormous number of total matches (e.g. 24 injury retirements out of 1771 analysed matches), a potential data interference may be considered as minor to none.

Every player competing in the $2^{\text {nd }}$ tournament week is part of the $1^{\text {st }}$ tournament week totals, given the structure in which Grand Slam tennis tournaments and professional tennis tournaments in general are played in (e.g. knockout system).

The analysed data presented by IBM pre-set categories like 'serve and volley points played,' 'serve and volley points won,' or 'aces' may be considered as limiting themselves, since the official category definitions are most reasonable, but ultimately non-verifiable preset definitions providing the used official data. Furthermore, the pre-set categories like ' $1{ }^{\text {st }}$ serve points won' present the outcome, but not the content of the game, since the $1^{\text {st }}$ serve itself not necessarily decided the point.

The comparability of the collected findings is limited to certain areas. All analysed matches were played on 
R. Grambow, C. O’Shannessy, P. Born, D. Meffert, T. Vogt, Ladies serve efficiency development

grass court by elite women, which must be taken under consideration when comparing the present study findings and conclusions with e.g. those for clay court or hard court tournaments or men's or junior tennis tournaments.

\section{Conclusions}

The aim of the present study was to analyse elite women's serve efficiency over an extended period of time and to look for possible keys on the way to succeed at the highest possible stage, in order to be able to suggest present and future practice patterns. Therefore, the study analysed all played singles matches at the Ladies Wimbledon Championships between 2002 and 2015. In order to examine possible differences within the women's world class, the data was not only analysed over time but also compared the $1^{\text {st }}$ tournament week totals with the $2^{\text {nd }}$ tournament week totals. The findings provide long-term evidence for an increased serve efficiency development, particularly for an increased serve success and better serve performances. Over time, the rates for service games won, points won on $1^{\text {st }}$ serve, and served aces increased, while, simultaneously, the number of served double faults decreased. These observations are consistent for tournament totals and most pronounced in the $1^{\text {st }}$ tournament week totals, whereas the $2^{\text {nd }}$ tournament week totals were unaffected between 2002 and 2015. Thus, a more balanced women's world class may be suggested with the extended world class having closed in over the analysed 14 years (developments in the $1^{\text {st }}$ tournament week totals; however, not in the $2^{\text {nd }}$ tournament week totals, which may result from better performances in the first place). Furthermore, it seems important to emphasize that the findings for the $1^{\text {st }}$ tournament week totals compared with the $2^{\text {nd }}$ tournament week totals are in favour of women competing in the $2^{\text {nd }}$ tournament week; this concerns served aces and success rates for service games won and $1^{\text {st }}$ serve points won. Interestingly, $2^{\text {nd }}$ serve points won over the analysed period are the only analysed serve success or serve performance parameter which showed no significant improvement over time. Moreover, $2^{\text {nd }}$ serve points won are the only parameter where the $1^{\text {st }}$ tournament week totals showed advantages over the $2^{\text {nd }}$ tournament week totals (e.g. in 8 out of 14 analysed years). This could be related directly to an increased return of serve quality by the (last 16) women competing in the $2^{\text {nd }}$ tournament week.

With this, future research may underpin whether a good $2^{\text {nd }}$ serve leading to higher success rates on the $2^{\text {nd }}$ serves effectively has a smaller impact on the way to succeed at the highest level in elite female tennis (e.g. winning Wimbledon), hinting to the importance of the return of serve, especially returning $2^{\text {nd }}$ serves. Eventually, this may suggest an easy chance for player improvement and, thus, possible separation from competitors; future practice patterns may benefit from the above considerations. In this regard, the long-term analyses of the present study also provide evidence for a gradually diminishing serve and volley strategy, although success rates of serve and volley play remained stable (at around 65\%). Future research may also investigate a possible transferability of the findings, e.g. with respect to other surfaces or strategies.

Conclusively, an increased serve efficiency (serve success and serve performance) over time indicates a more extended world class in women's elite grass court tennis and underlines the importance of good serving and the necessity of implementing this in professional practice.

\section{Coaching implications}

Following the findings of this study, possible guidelines as presented could be implemented in current and future practice. The observed winning percentages on $1^{\text {st }}$ serves $(64-70 \%)$ and $2^{\text {nd }}$ serves $(45-50 \%)$ should serve as benchmarks:

- In the $2^{\text {nd }}$ serve drill, the player has to play 20 points and is allowed to serve only 1 serve per point ( $2^{\text {nd }}$ serve). The player has to win at least 9 points to succeed; every number over 9 points has to be considered very good. If the player fails to reach the 9 points, the drill has to be done again.

- In the $1^{\text {st }}$ serve drill, the player has to play 20 points and is allowed to serve only $1^{\text {st }}$ serves. The point will start only after a successful $1^{\text {st }}$ serve, even if the player needs more attempts. The player has to win at least 13 points; every number over 13 points has to be considered very good. If the player fails to reach the 13 points, the drill has to be done again.

- Both drills playing at least 20 points will take some time, but underline the importance of the serve (and the return of serve for the training partner) and reflect the percentage of how much the serve, return, and opening shots should be implemented in the modern tennis practice. It should also be preferred to outplay the points instead of only serving (which nevertheless should also be done), since the contemplated winning percentages relate not only to the serve alone, but also to the gameplay afterwards. 
The findings show elite women serve more double faults than aces, but players competing in the $2^{\text {nd }}$ tournament week (last 16) achieve a slightly positive ratio. Nevertheless, a drill for $2^{\text {nd }}$ serves in order to decrease the number of double faults in elite women's tennis seems beneficial. The presented numbers relate to professional practice:

- Each service box should be split up into 3 zones (wide, body, and centre) in order to have 6 different target zones acting as levels $1-6$. The player may choose where to start and serve five $2^{\text {nd }}$ serves aiming for the same target zone. When serving all five $2^{\text {nd }}$ serves successful to the chosen zone, the player reaches the second level (new target zone). With 4 successful serves, the player stays in the current level and serves again 5 serves in order to reach the next level. With 3 successful serves, the player has to go 1 level down and try to pass the previous level successful again. With 2 or less successful $2^{\text {nd }}$ serves, the player has to start from level 1 all over again. The drill finishes with 5 successful serves at level 6 . Exercising this drill secures a high number of $2^{\text {nd }}$ serves being served by the player, while getting to know the player's favourite serving directions (interesting for the player and the coach). In this way, the player may know where to aim in match situations, while being under pressure. In addition, the less favourite target zones may be trained more in the future.

- Alternatively, the drill may be used for psychological practice as well if (1) players compete against a training partner and (2) have to announce deciding serves (e.g. the final $\left(5^{\text {th }}\right)$ serve after successfully hitting the previous 4 serves to a target zone or hitting the deciding serve for a restart at level 1 , in order to be watched serving the final attempt by the coach and the training partner(s).

\section{Acknowledgements}

The authors would like to thank busy bee Stefan Laux for his assistance during data analyses. Also, the authors would like to thank the three unknown reviewers for their valuable comments raised during the revision process.

\section{Disclosure statement}

No author has any financial interest or received any financial benefit from this research.

\section{Conflict of interest}

The authors state no conflict of interest.

\section{References}

1. Ma S-M, Liu C-C, Tan Y, Ma S-C. Winning matches in Grand Slam men's singles: an analysis of player performance-related variables from 1991 to 2008. J Sports Sci. 2013;31(11):1147-1155; doi: 10.1080/02640414. 2013.775472.

2. Maquirriain J, Baglione R, Cardey M. Male professional tennis players maintain constant serve speed and accuracy over long matches on grass courts. Eur J Sport Sci. 2016;16(7):845-849; doi: 10.1080/17461391. 2016.1156163.

3. Grambow R, O’Shannessy C, Born P, Meffert D, Vogt T. Serve efficiency development at Wimbledon between 2002 and 2015: a longitudinal approach to impact tomorrow's tennis practice. Hum Mov. 2020;21(1):65-72; doi: $10.5114 / \mathrm{hm} .2020 .88155$.

4. Crespo M, Reid M, Miley D. The role of sport science in tennis coaching. In: Crespo M, Reid M, Miley D (eds.), Applied sport science for high performance tennis Proceedings of the $13^{\text {th }}$ ITF Worldwide Coaches Workshop. Vilamoura: International Tennis Federation; 2003; 21-25.

5. Takahashi H, Wada T, Maeda A, Kodama M, Nishizono H, Kurata H. Time analysis of three decades of men's singles at Wimbledon. In: Lees A, Cabello D, Torres G (eds.), Science and racket sports IV. London: Routledge; 2008; 239-246.

6. Meffert D, O’Shannessy C, Born P, Grambow R, Vogt T. Tennis serve performances at break points: approaching practice patterns for coaching. Eur J Sport Sci. 2018;18(8):1151-1157; doi: 10.1080/17461391.2018. 1490821.

7. Knight G, O’Donoghue P. The probability of winning break points in Grand Slam men's singles tennis. Eur J Sport Sci. 2012;12(6):462-468; doi: 10.1080/17461391. 2011.577239.

8. Meffert D, O’Shannessy C, Born P, Grambow R, Vogt T. Tennis at tiebreaks: addressing elite players' performance for tomorrows' coaching. Ger J Exerc Sport Res. 2019;49(3):339-344; doi: 10.1007/s12662-01900611-3.

9. Pollard G, Cross R, Meyer D. An analysis of ten years of the four Grand Slam men's singles data for lack of independence of set outcomes. J Sports Sci Med. 2006; 5(4):561-566.

10. Carboch J. Comparison of game characteristics of male and female tennis players at grand-slam tournaments in 2016. Trends Sport Sci. 2017;24(4):151-155; doi: 10.23829/TSS.2017.24.4-2.

11. Reid M, Morgan S, Whiteside D. Matchplay characteristics of Grand Slam tennis: implications for training and conditioning. J Sports Sci. 2016;34(19):17911798; doi: 10.1080/02640414.2016.1139161.

12. O’Donoghue GP, Brown E. The importance of service in Grand Slam singles tennis. Int J Perform Anal Sport. 2008;8(3):70-78;doi:10.1080/24748668.2008.11868449. 


\section{HUMAN MOVEMENT}

R. Grambow, C. O’Shannessy, P. Born, D. Meffert, T. Vogt, Ladies serve efficiency development

13. Barnett T, Meyer D, Pollard G. Applying match statistics to increase serving performance. Med Sci Tennis. 2008;13(2):24-27.

14. O’Donoghue P, Ingram B. A notational analysis of elite tennis strategy. J Sports Sci. 2001;19(2):107-115; doi: 10.1080/026404101300036299.

15. O’Donoghue PG. The most important points in Grand Slam singles tennis. Res Q Exerc Sport. 2001;72(2): 125-131; doi: 10.1080/02701367.2001.10608942.

16. Cui Y, Gómez M-Á, Gonçalves B, Sampaio J. Performance profiles of professional female tennis players in Grand Slams. PLoS One. 2018;13(7):e0200591; doi: 10.1371/journal.pone.0200591.

17. O'Donoghue P, Liddle D. A match analysis of elite tennis strategy for ladies' singles on clay and grass surfaces. In: Hughes M, Maynard I, Lees A, Reilly T (eds.), Science and racket sports II. London: Taylor \& Francis; 2002; 247-253.

18. Kovalchik SA, Bane MK, Reid M. Getting to the top: an analysis of 25 years of career rankings trajectories for professional women's tennis. J Sports Sci. 2017;35(19): 1904-1910; doi: 10.1080/02640414.2016.1241419.

19. Del Corral J, Prieto-Rodríguez J. Are differences in ranks good predictors for Grand Slam tennis matches? Int J Forecast. 2010;26(3):551-563; doi: 10.1016/j.ijforecast.2009.12.006.

20. Weber K, Born P. The special significance of the expanded game opening in competitive tennis. Justification, guidelines, and implication in practical training [in German]. Leistungssport. 2012;42(6):26-32.

21. Weber K, Exler T, Marx A, Pley C, Röbbel S, Schäffkes C. Faster serves, shorter rallies and higher time pressure for groundstrokes in world-class tennis [in German]. Leistungssport. 2010;40(5):36-42.

22. Dindar MD, Toksöz İ, Taşkın C, Uluçam E. Analysis of the serves in the men's semi-final and final competitions of Wimbledon tennis tournament. Sport Sci. 2011;6(3):185-192.

23. Nowak M, Panfil R. Scoring abilities in the game of tennis - a pragmatic study of unique cases. Hum Mov. 2012;13(4):313-322; doi: 10.2478/v10038-012-0036-z.

24. Ferrauti A, Bastiaens K. Short-term effects of light and heavy load interventions on service velocity and precision in elite young tennis players. Br J Sports Med. 2007;41(11):750-753; doi: 10.1136/bjsm.2007.036855.

25. Hernández-Davo H, Urbán T, Sarabia JM, Juan-Recio C, Moreno FJ. Variable training: effects on velocity and accuracy in the tennis serve. J Sports Sci. 2014; 32(14):1383-1388; doi: 10.1080/02640414.2014.891290.

26. Barnett T, Games S. How the court surface is affecting the serve-and-volley. J Med Sci Tennis. 2010;15(3):26-28.

27. Cohen J. A power primer. Psychol Bull. 1992;112(1): 155-159; doi: 10.1037//0033-2909.112.1.155.

28. Hopkins WG, Marshall SW, Batterham AM, Hanin J. Progressive statistics for studies in sports medicine and exercise science. Med Sci Sports Exerc. 2009;41(1): 3-13; doi: 10.1249/MSS.0b013e31818cb278.
29. Filipcic A, Zecic M, Reid M, Crespo M, Panjan A, Nejc S. Differences in performance indicators of elite tennis players in the period 1991-2010. JPES. 2015;15(4): 671-677; doi: 10.7752/jpes.2015.04102.

30. Schönborn R. Optimal tennis training: the path to successful tennis from novices to world class [in German]. Balingen: Spitta; 2010. 